\title{
Analisis Pedagogical Content Knowledge Mahasiswa Calon GURU PENDIDIKan Matematika
}

\author{
Ade Irfan'1, Anzora $^{2}$ dan Tuti Marjan Fuadi ${ }^{3}$ \\ 1Pendidikan Matematika, FKIP, Universitas Abulyatama, \\ Jl. Blang Bintang Lama Km 8,5 Lampoh Keudee, Aceh Besar, Aceh \\ adeirfan_matematika@abulyatama.ac.id \\ ${ }^{2}$ Pendidikan Matematika, FKIP, Universitas Abulyatama \\ Jl. Blang Bintang Lama Km 8,5 Lampoh Keudee, Aceh Besar, Aceh \\ anzora199@gmail.com \\ ${ }^{3}$ Pendidikan Biologi, FKIP, Universitas Abulyatama \\ Jl. Blang Bintang Lama Km 8,5 Lampoh Keudee, Aceh Besar, Aceh \\ tutimarjan_biologi@abulyatama.ac.id
}

\begin{abstract}
Abstrak
Penelitian ini bertujuan untuk mengetahui pedagogical content knowledge mahasiswa calon guru pada program studi pendidikan matematika Fakultas Keguruan dan IImu Pendidikan Universitas Abulyatama Aceh. Penelitian ini menggunakan pendekatan kualitatif dengan desain triangulasi, dimana peneliti mengumpulkan data dari beberapa sumber dan metode yang berbeda, membandingkan hasilnya dan menggunakan hasil temuan untuk melihat apakah saling memvalidasi satu sama lainnya. Data tentang pedagogical content knowledge mahasiswa calon guru kemudian dipaparkan apa adanya sehingga jenis penelitian ini dikategorikan dengan penelitian deskriptif-kualitatif dengan desain triangulasi. Adapun subjek dalam penelitian ini adalah 3 (tiga) orang mahasiswa program studi pendidikan matematika FKIP Universitas Abulyatama yang telah menyelesaikan matakuliah micro teaching atau sedang praktek pengalaman lapangan. Berdasarkan penelitian diketahui bahwa content knowledge mahasiswa calon guru program studi pendidikan Matematika FKIP Universitas Abulyatama berada pada kategori rendah sampai sedang dengan skor 1 sampai dengan 2. Sementara itu, pedagogical knowledge mahasiswa calon guru program studi pendidikan matematika FKIP Universitas Abulyatama berada pada kategori rendah sampai sedang dengan skor 1 sampai dengan 2 .

Kata Kunci: Analisis, Pedagogical Content Knowledge, mahasiswa calon guru
\end{abstract}

\begin{abstract}
This study aimed to determine pedagogical content knowledge of prospective students in mathematics education program Faculty of Teacher Training and Education University Abulyatama Aceh. This study used a qualitative approach with triangulation design, in which the researchers collected data from several different sources and methods, compared the results and used the findings to see if mutually validate each other. Data about pedagogical content knowledge of prospective teacher students were then presented as it is so that this type of research was categorized by descriptive-qualitative research with triangulation design. The subjects in this study were 3 (three) students of mathematics education program of FKIP University Abulyatama who had completed micro teaching courses or were practicing field experience. Based on the research, it is known that the content knowledge of the prospective teachers of the study program of Mathematics Education of FKIP Universitas Abulyatama was in the low to moderate category with the score of 1 to 2. Meanwhile, pedagogical knowledge of the candidate of the teacher of the mathematics education program of FKIP Universitas Abulyatama was in low to moderate category with a score of 1 to 2.

Keyword: Analysis, Pedagogical Content Knowledge, pre service teacher
\end{abstract}




\section{Pendahuluan}

Pendidikan yang berkualitas sangat dipengaruhi oleh guru yang berkualitas. Dengan kata lain, hanya guru yang berkualitas yang mampu meningkatkan kualitas pendidikan.

Harapan untuk mendapatkan guru yang berkualitas seakan sirna setelah pemerintah melakukan Uji Komptensi Guru (UKG) pada tahun 2015 lalu yang menunjukkan bahwa rata-rata hasil kompetensi guru masih jauh dari nilai ratarata standar yang diharapkan (nuptk.net, 2016). Ada baiknya untuk institusi yang mendidik calon guru agar memperhatikan hal ini, sehingga guru tidak hanya pandai dalam menyelesaikan suatu permasalahan matematis tetapi juga pandai dalam membuat permasalahan dengan berbagai situasi/tingkatan sesuai dengan apa yang dibutuhkan siswanya. (Afriansyah, 2017)

Kondisi lain yang lebih miris adalah calon guru yang nantinya akan menjadi guru dan diharapkan dapat meningkatkan kualitas pendidikan justru mengalami kendala dalam mengajar. Mereka sering merasakan kesenjangan antara praktek mengajar dan teori yang mereka peroleh (Holt-Reynolds, 2000).

Sementara itu, berdasarkan beberapa studi menunjukkan bahwa calon guru seringkali sangat kurang dalam pemahaman konseptual dari konten yang akan mereka ajarkan. Para calon guru sering memahami subject matter knowledge (SMK) secara terpisah-pisah dan sangat tak terorganisasi sehingga mengakibatkan kesulitan untuk mengakses pengetahuan tersebut ketika mereka harus mengajarkannya (Gess-Newsome, 2011). Problem lain yang mereka hadapi adalah kurangnya kemampuan mereka dalam membuat rencana pembelajaran yang berdampak timbulnya kesulitan dalam praktek mengajar di kelas (Kapyla, et al, 2009)

Fakta lain, di Banda Aceh banyak mahasiswa calon guru dari berbagai perguruan tinggi tidak siap ketika melaksanakan Praktek Pengalaman Lapangan (PPL) dan terkesan seadanya. Berdasarkan hasil wawancara penulis dengan beberapa guru senior di Banda Aceh diketahui bahwa, banyak guru PPL tidak menguasai materi dan tidak memahami strategi pembelajaran yang sesuai dengan materi yang akan diajarkan. Para mahasiswa calon guru tersebut cenderung menerapkan strategi pembelajaran yang baru menurut mereka dengan mengabaikan kesesuaian strategi pembelajaran dengan materi yang akan diajarkan dan tidak memperdulikan keadaan peserta didik. Akibatnya guru PPL dianggap merupakan salah satu "biang" penyebab rendahnya nilai peserta didik.

Padahal program PPL diharapkan dapat menjadi pengalaman bagi mahasiswa calon guru dalam mempraktekkan semua teori dan pengetahuan (teori) yang telah mereka peroleh di bangku perkuliahan. Selain itu, guru PPL juga diharapkan dapat menularkan strategi mengajar yang baru dan hal-hal yang benar dalam merancang dan menyusun rencana pelaksanaan pembelajaran kepada para guru-guru. 
Keadaan di atas jika terus dibiarkan dan tidak mendapat perhatian serius dari semua pihak akan menjadi fenomena baru yang kemudian berdampak pada kualitas pendidikan. Hal ini dikarenakan mahasiswa calon guru yang merupakan generasi selanjutnya dari guru akan semakin jauh dari kualitas yang diharapkan. Jika mahasiswa calon guru tidak dibekali dengan kemampuan mengajar dan penguasaan materi yang baik maka bisa dipastikan harapan untuk mendapatkan guru yang berkualitas hanya sebatas "mimpi" belaka.

Dalam pandangan paham konstruktivis, mengajar bukan sekedar transfer pengetahuan semata, melainkan suatu kegiatan yang memungkinkan siswa membangun sendiri pengetahuannya. Atas dasar inilah maka seorang guru harus memiliki pengetahuan tentang materi dan pedagogi yang efektif, tepat dan sesuai untuk mengajarkan siswa dengan mudah. Lee Shulman (dalam Van Driel et al:2010) menyebutnya dengan istilah Pedagogical Content Knowledge (PCK).

Shulman (dalam Van Driel et al, 2010) menyatakan PCK merupakan suatu pengetahuan yang mengkombinasikan antara pengetahuan materi (content knowledge) dan pengetahuan mengajar (pedagogy). Dengan demikian, mengetahui PCK guru bahkan mahasiswa calon guru sangat penting untuk menciptakan lulusan pendidikan yang berkualitas dalam rangka meningkatkan mutu pendidikan nasional.
Fakultas Keguruan dan Ilmu Pendidikan (FKIP) Universitas Abulyatama (Unaya) Aceh merupakan salah satu LPTK yang ada di Aceh. Salah satu program studi di Fakultas ini adalah program studi pendidikan matematika. Prodi ini telah menghasilkan banyak lulusan untuk memenuhi kuota guru matematika di Aceh. Namun, analisisis terhadap PCK lulusan dari prodi pendidikan matematika FKIP Unaya selama ini belum pernah dilakukan.

Analisis PCK sangat penting dilakukan dengan tujuan untuk mengetahui kemampuan Pedagogical Content Knowledge mahasiswa calon guru di prodi pendidikan matematika FKIP Unaya Sehingga analisis terhadap PCK mahasiswa calon guru ini diharapkan dapat menjadi salah satu alat evaluasi bagi proses perkuliahan yang selama ini berlangsung di prodi pendidikan matematika FKIP Unaya dalam rangka meningkatkan kualitas lulusan.

Pedagogical content knowledge (PCK) dipandang sebagai perpaduan antara pengetahuan seorang guru dalam menguasai isi materi ajar dan pedagogik dalam memahami suatu masalah, topik yang disesuaikan dengan minat dan kemampuan siswa yang efektif untuk topik khusus, seperti pemahaman tentang cara membuat topik khusus itu mudah atau sulit untuk dipelajari (Eggen et al., 2007).

Seorang guru profesional harus memiliki pengetahuan dan kemampuan PCK yang baik karena sebagai agen perubahan (the agent of change). Guru 
harus terus mengembangkan proses mengajarnya di kelas dan calon guru terus melatih kemampuannya dalam merancang pembelajaran, salah satunya dengan memahami PCK. Seorang guru dan calon guru harus mampu memahami PCK karena seorang guru harus familiar dengan konsep, alternatif dan kesulitan yang dihadapi siswa dengan beragam latar belakang serta dapat mengorganisasikan, menyusun, menjalankan dan menilai materi subjek, semua itu terangkum dalam PCK (Shulman, 1986). Shulman juga menyatakan bahwa pedagogical knowledge berkaitan dengan "cara dan proses mengajar yang meliputi pengetahuan tentang manajemen kelas, tugas, perencanaan pembelajaran dan pembelajaran siswa".

Berdasarkan penjelasan di atas, PCK dalam penelitian ini adalah pemahaman mahasiswa calon guru prodi pendidikan matematika FKIP Universitas Abulyatama dalam memilih dan menerapkan strategi pembelajaran yang tepat dan efektif yang sesuai dan menjadikan materi yang diajarkan mudah dipahami oleh siswa.

PCK yang dimiliki oleh seorang guru memuat beberapa komponen penting yang harus diamati. Hill dkk, (2008) dalam sebuah hasil penelitian mengemukakan contoh komponen yang diamati berkaitan dengan PCK yaitu meliputi kesulitan yang dialami siswa ketika belajar, representasi yang paling bermanfaat untuk menjelaskan suatu materi pelajaran, miskonsepsi oleh siswa, dan menarik atau tidaknya materi pelajaran bagi siswa.

Chick dan Baker (2006; 60-67) mengatakan bahwa dalam menyusun kerangka kerja dari PCK banyak penulis yang menekankan representasi. sementara lainnya memasukkan pengetahuan tentang berpikir siswa, teks dan materi, apa yang membuat suatu topik mudah dan sulit, dan strategi pengajaran.

Berdasarkan hal tersebut, Chick kemudian menawarkan kerangka kerja untuk menganalisis PCK guru. Adapun kerangka kerja ini terbagi menjadi 3 (tiga) bagian yaitu; (1) Clearly PCK, memuat aspek-aspek yang merupakan gabungan dari pedagogik dan konten; (2) Content Knowledge in a Pedagogical Context, memuat aspek-aspek yang berkaitan langsung dengan konten; (3) Pedagogical Knowledge in a Content Context, mencakup pengetahun yang disusun dari pedagogik. Kerangka kerja tersebut dapat diperhatikan Tabel 1.

Tabel 1.

Kerangka Kerja untuk menganalisis Pedagogical Content Knowledge

\begin{tabular}{cc}
\hline PCK category & Evicent when the teacher ... \\
\hline $\begin{array}{c}\text { Clearly PCK } \\
\text { Teaching strategies }\end{array}$ & $\begin{array}{c}\text { Discusses or uses strategies or approaches for } \\
\text { teaching a mathematical concept }\end{array}$ \\
\hline Student thinking & $\begin{array}{c}\text { Discusses or addresses student ways of thinking } \\
\text { about a concept or typical levels of understanding }\end{array}$ \\
\hline
\end{tabular}




\begin{tabular}{|c|c|}
\hline Student thinking-misconceptions & $\begin{array}{l}\text { Discusses or addresses student misconceptions } \\
\text { about a concept }\end{array}$ \\
\hline Cognitive demands of task & $\begin{array}{l}\text { Identifies aspects of the task that affect its } \\
\text { complexity }\end{array}$ \\
\hline $\begin{array}{l}\text { Appropriate and detailed representations of } \\
\text { concepts }\end{array}$ & Concept (can include materials of diagrams) \\
\hline Knowledge of resource & $\begin{array}{c}\text { Discusses/uses resources available to support } \\
\text { teaching }\end{array}$ \\
\hline Curriculum knowledge & Discusses how topics fit into the curriculum \\
\hline Purpose of content knowledge & $\begin{array}{c}\text { Discusses reasons for conetnt being included in the } \\
\text { curriculum or hoe it might be used. }\end{array}$ \\
\hline \multicolumn{2}{|l|}{ Content knowledge in a pedagogical context } \\
\hline $\begin{array}{c}\text { Profound understanding of fundamental } \\
\text { mathematics }\end{array}$ & $\begin{array}{l}\text { Exhibits deep and thorough conceptual } \\
\text { understanding of identified aspecs of mathematics }\end{array}$ \\
\hline Deconstructing content to key components & $\begin{array}{l}\text { Concept that are fundamental for understanding } \\
\text { and applying hat concept }\end{array}$ \\
\hline Mathematical structure and connections & $\begin{array}{c}\text { Makes connections between concepts and topics, } \\
\text { including interdependence of concepts }\end{array}$ \\
\hline Procedural knowledge & $\begin{array}{l}\text { Displays skills for solving mathematical problems } \\
\text { (conceptual understanding nedd not be evident) }\end{array}$ \\
\hline Methods of solution & $\begin{array}{l}\text { Demonstrates a method for solving a maths } \\
\text { problem }\end{array}$ \\
\hline \multicolumn{2}{|l|}{ Pedagogical knowledge in a content contexxt } \\
\hline Goals for learning & $\begin{array}{c}\text { Describes a goal for student's learning may or may } \\
\text { not be related to spesific mathematics content) }\end{array}$ \\
\hline Getting and maintaining student focus & Discusses strategies for engaging students \\
\hline Classroom techniques & Discusses generic classroom practices \\
\hline
\end{tabular}

Sumber: Chick, Baker, Pham \& Cheng, 2006

Pedagogical Content Knowledge (PCK) mahasiswa calon guru akan dikaji berdasarkan kerangka kerja yang dikembangkan oleh Chick et al. Instrumen tersebut digunakan setelah dilakukan penyesuaian terhadap indikator pada setiap kategori dan melengkapkannya dengan rubrik.

Penelitian ini bertujuan untuk mengetahui pedagogical content knowledge mahasiswa calon guru prodi pendidikan Matematika FKIP Universitas Abulyatama Aceh.

\section{Metode}

\section{Mosharafa: Jurnal Pendidikan Matematika}

Volume 7, Nomor 2, Mei 2018
Penelitian ini merupakan penelitian deskriptif-kualitatif dengan desain triangulasi. Adapun subjek dalam penelitian ini adalah 3 (tiga) orang mahasiswa Program Studi Pendidikan Matematika FKIP Universitas Abulyatama yang telah menyelesaikan matakuliah microteaching atau sedang praktek pengalaman lapangan. Instrumen penelitian ini adalah lembar tugas berbasis masalah, pedoman wawancara, dan lembar observasi. Analisis data yang digunakan dalam penelitian ini berdasarkan analisis data yang dikembangkan oleh Miles dan Huberman (1992), yaitu reduksi data, penyajian data, dan penarikan kesimpulan/verifikasi. 


\section{Hasil dan Pembahasan}

\section{Content Knowledge Mahasiswa}

Berdasarkan hasil tugas pemetaan konsep yang diberikan kepada mahasiswa calon guru dalam mengidentifikasi penguasan materi ajar diketahui bahwa semua mahasiswa calon guru mampu membuat peta konsep namun masih tidak lengkap (gambar 1).

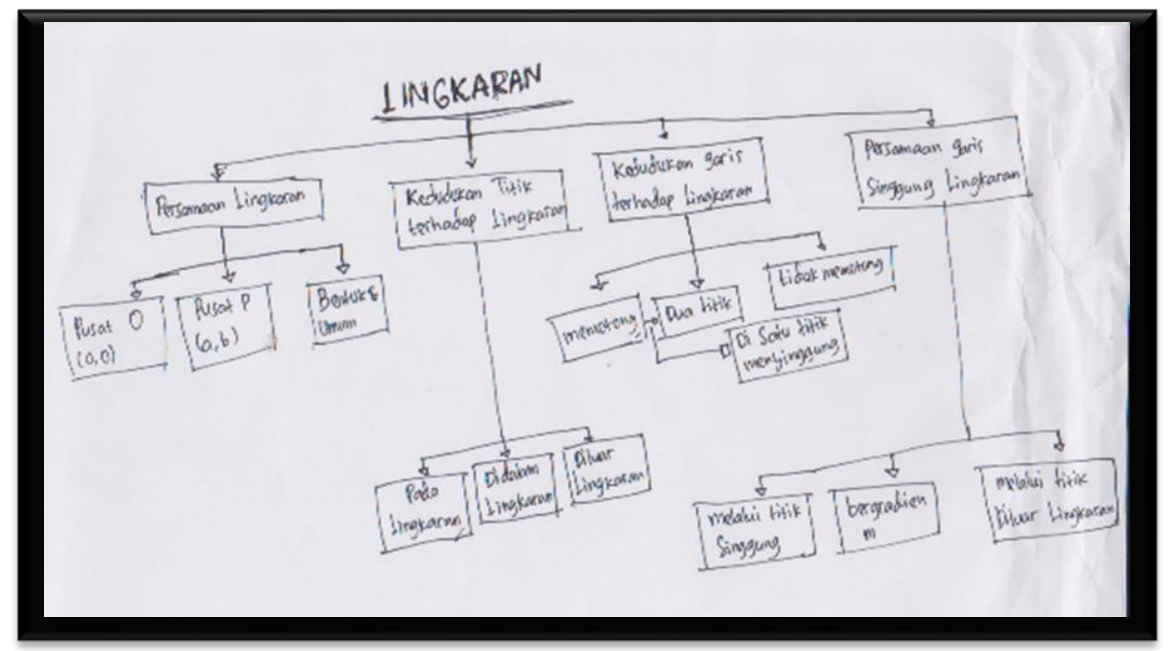

Gambar 1. Peta Konsep Lingkaran

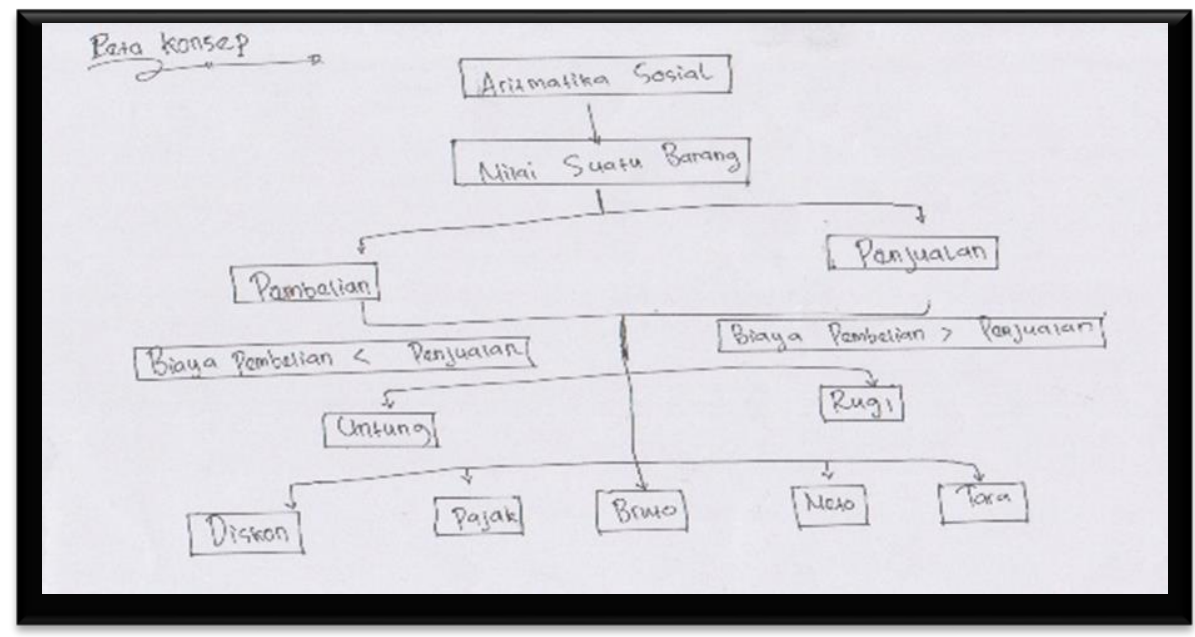

Gambar 2. Peta Konsep Aritmatika Sosial 


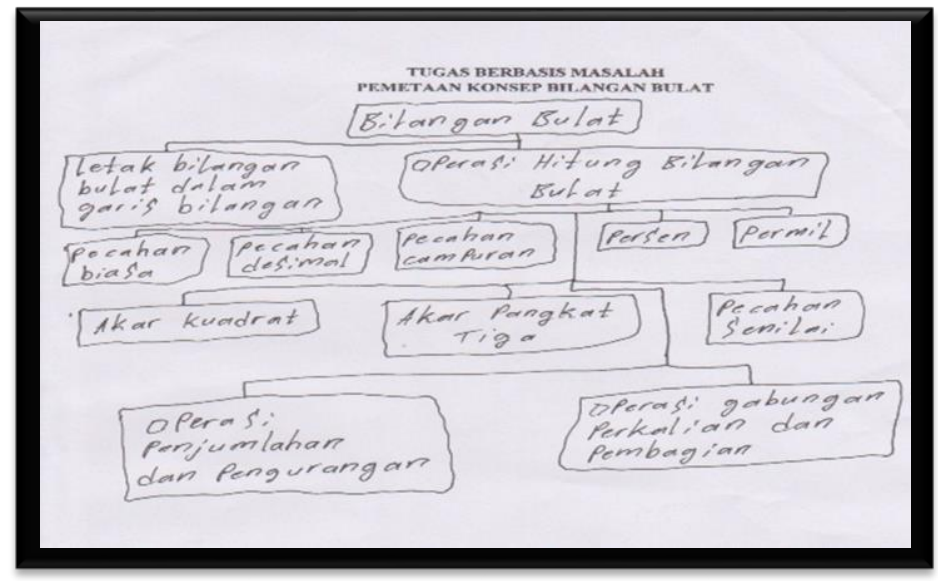

Gambar 3. Peta Konsep Bilangan Bulat

Semua mahasiswa membuat peta (network tree) namun mereka tidak konsep dengan tidak terlebih dahulu mengetahui jenis peta konsep dengan menentukan topik dengan tegas meskipun menentukan bahan bacaan sebelumnya. rinci. Mahasiswa juga tidak mengurutkan konsep terlebih dahulu sebelum Mahasiswa calon guru juga nampak sukar memebuat peta konsep. Pada setiap garis dalam menentukan ide pendukungnya. penghubung pada peta konsep yang Mereka tidak menuliskan kata dibuat oleh mahasiswa juga belum penghubung antara ide pokok dengan ide pendukung dan antara ide pendukung yang saling berkaitan. Berdasarkan mencantumkan kata penghubung keterangan garis hubung tersebut. Semua mahasiswa juga belum mampu wawancara diketahui bahwa semua mengembangkan peta konsep tersebut mahasiswa membuat peta konsep dengan dimana tidak konsistennya penambahan tidak memperhatikan langkah-langkah konsep baru pada setiap peta konsep pembuatan peta konsep dengan baik. lainnya. Adapun indikator ketercapaian Meskipun mahasiswa telah Sehingga dan skor content knowledge mahasiswa kaitan antara ide pendukung dan ide utama menjadi kurang jelas. calon guru dipaparkan pada Tabel 2

Meskipun semua mahasiswa membuat peta konsep dengan jenis pohon jaringan

Tabel 2

Indikator ketercapaian dan skor content knowledge mahasiswa calon guru

\begin{tabular}{|c|c|c|c|}
\hline \multicolumn{4}{|c|}{ PCK Mahasiswa Calon Guru } \\
\hline \multicolumn{2}{|c|}{$\begin{array}{c}\text { Indikator } \\
\text { Content Knowledge }\end{array}$} & Deskripsi & Skor \\
\hline $\begin{array}{l}\text { Struktur } \\
\text { koneksi }\end{array}$ & Matematika dan & $\begin{array}{l}\text { Mahasiswa calon guru tidak membuat koneksi } \\
\text { antara konsep dan topik, tidak menuliskan kata } \\
\text { hubung yang jelas antara ide utama dan ide } \\
\text { pendukung. }\end{array}$ & 2 \\
\hline
\end{tabular}




\begin{tabular}{llll}
\hline $\begin{array}{l}\text { Struktur dan } \\
\text { matematika }\end{array}$ & koneksi & Mahasiswa calon guru masih belum mampu dalam & 2 \\
& membuat koneksi yang benar antara ideu utama & \\
& dan ide pendukung serta dalam mengaitkan \\
& materi prasyarat & & \\
\hline Pengetahuan prosedur & Mahasiswa mampu mengidentifikasi ide utama & 1 \\
& dan ide pendukung namun tidak mampu \\
& membuat hubungan yang benar. & \\
\hline
\end{tabular}

\section{Pedagogical Mahasiswa}

Data pedagogical knowledge mahasiswa calon guru diperoleh dengan menganalisis rancangan Rencana Pelaksanaan Pembelajaran, dan proses pembelajaran yang dilakukan mahasiswa di kelas. Berdasarkan hasil penelitian diketahui bahwa semua mahasiswa dapat membuat RPP dengan telah mencantumkan identitas RPP, kompetensi inti, kompetensi dasar, indikator pencapaian kompetensi, dan tujuan pembelajaran, materi ajar, skenario pembelejaran dan sumber belajar serta soal latihan dan tugas. Mahasiswa calon guru juga sudah menggunakan berbagai strategi pembelajaran, model dan metode dalam merancang rencana pelaksanaan yang mereka buat. Meskipun demikian, semua mahasiswa tidak dapat memberikan penjelasan tentang kesesuaian antara model dengan materi yang akan diajarkan. Sementara itu, berdasarkan hasil observasi terhadap pelaksanaan proses pembelajaran mahasiswa di kelas diperoleh informasi bahwa mahasiswa mengajar sesuai dengan rencana yang telah dirumuskan awalnya dalam RPP, meskipun demikian masih terdapat mahasiswa yang mengajar dengan tidak berpedoman pada rencana pelaksanaan pembelajaran yang telah dibuat. Diantara strategi pembelajaran yang diterapkan mahasiswa dalam proses pembelajaran adalah Problem Based Learning dan pendekatan saintifik. Mahasiswa calon guru tidak maksimal dalam memanfaatkan lembar kerja yang telah dibuat dan juga brosur pembelajaran yang telah disiapkan. Akibatnya banyak siswa yang tidak fokus dalam berdiskusi untuk menyelesaikan LKS yang diberikan. Peran mahasiswa calon guru sebagai fasilitator juga masih belum maksimal. Mahasiswa calon guru cenderung akhirnya menggunakan metode ceramah untuk menjelaskan materi yang diajarkan. Adapun indikator ketercapaian dan skor pedagogical knowledge mahasiswa calon guru dipaparkan pada Tabel 3 berikut ini:

Tabel 3

Indikator ketercapaian dan skor pedagogical knowledge mahasiswa calon guru

\begin{tabular}{|llcc|}
\hline \multicolumn{1}{|c|}{ PCK Mahasiswa Calon Guru } & \multicolumn{1}{c|}{ Deskripsi } & Skor \\
\multicolumn{1}{|c}{$\begin{array}{l}\text { Indikator } \\
\text { Pedagogical Knowledge }\end{array}$} & & & \\
\hline $\begin{array}{l}\text { Tujuan Pembelajaran Matematika } \\
\text { Secara Khusus }\end{array}$ & $\begin{array}{l}\text { Mahasiswa mampu menuliskan tujuan } \\
\text { pembelajaran yang terkait dengan materi pokok }\end{array}$ & 2 \\
\hline
\end{tabular}




\begin{tabular}{|c|c|c|}
\hline & yang diajarkan namun kurang lengkap & \\
\hline $\begin{array}{l}\text { Pengetahuan terhadap sumber } \\
\text { belajar }\end{array}$ & $\begin{array}{l}\text { Mahasiswa mampu menuliskan sumbe rbelajar } \\
\text { dari materi ajar namun masih belum lengkap }\end{array}$ & 2 \\
\hline $\begin{array}{l}\text { Mendapatkan dan menjaga fokus } \\
\text { siswa }\end{array}$ & $\begin{array}{l}\text { Mahasiswa masih belum mampu menjaga fokus } \\
\text { siswa dalam pelaksanaan proses pembelajaran }\end{array}$ & 1 \\
\hline $\begin{array}{l}\text { Menunjukkan pemahaman yang } \\
\text { mendalam mengenai dasar } \\
\text { matematika }\end{array}$ & $\begin{array}{l}\text { Mahasiswa mampu menjelaskan semua konsep } \\
\text { dari peta konsep yang dibuat namun masih belum } \\
\text { mampu dalam menjelaskannya secara praktek } \\
\text { kepada siswa dalam pembelajaran }\end{array}$ & 1 \\
\hline
\end{tabular}

\section{Pembahasan}

Berdasarkan hasil analisis PCK terhadap mahasiswa calon guru diketahui bahwa rentang kemampuan pedagogical content knowledge mahasiswa calon guru program studi pendidikan matematika FKIP Universitas Abulyatama berada pada skor 1 sampai dengan 2. Hal ini menunjukkan bahwa masih rendahnya kemampuan content knowledge dan pedagogical knowledge mahasiswa calon guru pada program studi pendidikan matematika FKIP Universitas Abulyatama. Kedaan ini akan berdampak buruk pada kemampuan bersaing lulusan. Dimana nantinya alumni program studi Pendidikan Matematika akan mengalami kesulitan dalam mengajar di sekolah. Hal ini sesuai dengan pendapat Ulgen (dalam Ozturan dkk., 2012), yang menyatakan bahwa seorang guru yang tidak mampu memahami proses pembelajaran konsep dan kondisi pengajaran yang tepat, dapat membuat siswa sulit untuk mempelajari konsep dan mengembangkan keterampilan belajar konsep.

Pada kategori content knowledge, untuk indikator tentang membuat koneksi antara konsep dan topik serta mengkaitkan sruktur dan koneksi matematika secara umum mahasiswa calon guru telah dapat menrancangnya. Akan tetapi penguasaan mahasiswa calon guru pada kategori content knowledge ini masih rendah, karena belum ada mahasiswa calon guru yang termasuk dalam skor 4, hanya terdapat pada skor 2 dimana mahasiswa calon guru dapat merancang peta konsep tersebut. Akan tetapi tidak terdapat kaitan antara ide pokok dengan ide pendukung terhadap materi yang dipilihnya.

Pada kategori pedagogical knowledge, untuk indikator tentang tujuan pembelajaran, sumber belajar, fokus siswa, kejelasan materi, keterampilan dalam pemecahan masalah, dan mendemostrasikan metode atau topik pada materi pembelajaran yang terkait secara umum mahasiswa calon guru telah dapat melaksanakannya. Akan tetapi penguasaan mahaiswa calon guru pada katagori pedagogical knowledge ini masih rendah, karena belum ada mahasiswa yang termaksud pada skor 4, hanya terdapat pada skor 2 dimana mahasiswa calon guru dapat merancang perangkat dan melaksanakan pembelajaran, tetapi kurangnya hubungan atau kesamaan antara rancangan dengan proses pembelajaran dan kurangnya pengetahuan 
pada metode atau strategi pada materi yang akan diajarkan.

\section{Penutup}

Berdasarkan paparan di atas maka dapat disimpulkan bahwa: (1) Content knowledge mahasiswa calon guru program studi pendidikan Matematika FKIP Universitas Abulyatama berada pada kategori rendah sampai sedang dengan skor 1 sampai dengan 2, (2) Pedagogical knowledge mahasiswa calon guru program studi pendidikan matematika FKIP Universitas Abulyatama berada pada kategori rendah sampai sedang dengan skor 1 sampai dengan 2 .

Adapun saran untuk penelitian selanjutnya yaitu perlu dilakukannya penelitian lebih lanjut terhadap mahasiswa baik mengenai penguasan materi ajar dan kemampuan mengajarnya dalam rangka meningkatkan kualitas Iulusan. Dalam pelaksanaan perkuliahan, para dosen diharapkan dapat selalu menekankan pada pemahaman content knowledge dan penguasaan pedagogical knowledge agar memperoleh lulusan yang berkualitas dan mampu bersaing dalam dunia kerja. Penelitian ini merupakan penelitian awal khususnya tentang pedagogical content knowledge mahasiswa calon guru pada program Studi pendidikan matematika FKIP Universitas Abulyatama dengan subjek yang sangat terbatas. Oleh karena itu perlu adanya penelitian yang lebih lanjut untuk mendapatkan hasil yang sempurna baik pada program studi pendidikan matematika maupun pada program studi lainnya agar diperoleh PCK mahasiswa calon FKIP secara menyeluruh.

\section{UCAPAN TERIMA KASIH}

Penulis mengucapkan terimakasih kepada Direktorat Riset dan Pengabdian Masyarakat (DRPM) Ditjen Penguatan dan Pengembangan Kemenristekdikti yang telah memberikan kesempatan kepada peneliti untuk memperoleh hibah pada skema penelitian dosen pemula dan kepada pihak universitas Abulytama yang telah memfasilitasi penelitian ini serta berbagai pihak yang telah membantu.

\section{Daftar Pustaka}

Afriansyah, E. A. (2017). Problem Posing sebagai Kemampuan Matematis. Mosharafa: Jurnal Pendidikan Matematika, 6(1), 163-180.

Chick, dan Baker. (2006). Pedagogical Content Knowledge for Teaching Primary Mathematics: A Case Study of Two Teachers.

Eggen, P \& Don K. (2007). Educational Psychology Windows on Classroom 7th ed, New Jersey: Pearson Education, Inc.

Gess, N. dkk. (2011). A PCK Rubric to sMeasure Teachers Knowledge of Inquiry Based Instruction Using Three Data Sources.

Hill, C. Heather. (2008). Unpacking Pedagogical Content Knowledge: conceptualizing and measuring teachers' topic-spesific knowledge of students. Jurnal for research in 
mathematics education. Vol. 39 no. 4. 372-400

Holt, Reynolds. (2000). what does the teacher do?: constructivist pedagogies and prospective teachers' beliefs about the role of a teacher. Teacher and teaching education. Vol. 1. No 16. 21-32

Kapyla, Markku, Et al. (2009). Influence of content knowledge on pedagogical content knowledge: the case of teaching photosynthesis and plant growth. International Journal of Science Education.

Ozturan, dkk. 2012. A qualitative Study on Teacher Candidates' Concept Knowledge Level.

Shulman, L. S. (1986'). Those Who Understand: Knowledge Growth in Teaching.

Shulman, L. S. $\left(1986^{\mathrm{b}}\right)$. Paradigms and research programs in the study of teaching. In M.C. Wittrock (Ed.), Handbook of research on teaching.

Shulman, L. S (1987). Knowledge and Teaching: Foundation of the New Reform. Harvard Educational Review.

Van Driel J.H.dkk. (1998). Developing Science Teacher's Pedagogical Content Knowledge.

Van Driel, J.H. dkk. (2010). Pedagogical content knowledge. ICLON-leiden University Graduate School of Teaching \& Monash University: Elsevier.Ltd http://nuptk.net.ujian ukg rata- rata nasional hasil ukg 2015 masih di bawah standar diakses pada 26 mei 2018.

\section{Riwayat Hidup PENULIS}

Ade Irfan, S.Pd.I, M.Pd.

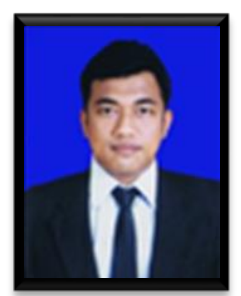

Lahir di Rambayan, tanggal o9 februari 1988, staf pengajar pengajar di Jurusan Pendidikan Matematika, Universitas Abulyatama. Studi S1 pendidikan Matematika UIN Ar-Raniry, Banda Aceh, lulus tahun 2010; S2 pendidikan Matematika, Universitas Negeri Surabaya, lulus tahun 2013, presenter di Internasional Seminar Modelling Of Mathematics tahun 2017.

\section{Anzora, S.Pd.I, M.Pd.}

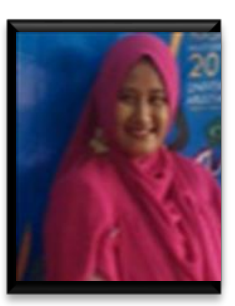

Lahir di Banda Aceh, tanggal 19 September 1988. Staf pengajar di Jurusan Pendidikan Matematika. Studi S1 pendidikan Matematika UIN ArRaniry, Banda Aceh, lulus tahun 2010; S2 pendidikan Matematika, Universitas Negeri Surabaya, lulus tahun 2013.

\section{Tuti Marjan Fuadi, S.Pd, M.Pd.}

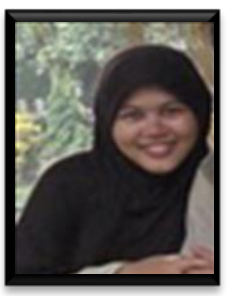

Lahir di Banda Aceh, tanggal 19 September 1988. Staf pengajar di Jurusan Pendidikan Biologi, Universitas Abulyatama Aceh. Studi S1 pendidikan Biologi Universitas Syiah Kuala, Banda Aceh, lulus tahun 2010; S2 pendidikan Biologi, Universitas Syiah Kuala, Lulus tahun 2013. 
This page is intentionally left blank 